\title{
EVOLUÇÃO DA ENFERMAGEM NO CONTEXTO DO HOSPITAL-ESCOLA: DEPOIMENTOS DE ENFERMEIROS REPRESENTANTES DA DÉCADA DE 70
}

Edna Paciência Vietta*

Marlene Uehara**

Kelly Ap. Silva Netto***

VIETTA, E.P.; UEHARA, M.: NETTO, K.A.S. Evolução da enfermagem do contexto do hospital-escola: depoimentos de enfermeiros representantes da década de 70 . Rev.latino-am.enfermagem, Ribeirão Preto, v. 4, n. 3, p. 135-154, dezembro de 1996.

Este estudo é parte de um projeto mais amplo que visa resgatar aspectos significativos relacionados a revolução da assistência de enfermagem da década de 50 a 90. Este resgate é feito através da técnica de depoimentos orais de enfermeiros em exército e aposentados, no contexto de um hospital-escola do interior paulista. $O$ presidente estudo particulariza os resultados obtidos, referentes a década de 70. Como resultado evidencia-se o esforço empreendido pelos enfermeiros na luta pelo reconhecimento e prestígio da profissão, as transformações intensas e profundas aos novos papéis da enfermeira enquanto líder da equipe e membro da equipe médica.

UNITERMOS: enfermagem, evolução da assistência de enfermagem, hospital-escola

\footnotetext{
* Prof. Titular do Departamento de Enfermagem Psiquiátrica e Ciências Humanas da Escola de Enfermagem de Ribeirão Preto da Universidade de São Paulo

** Bolsista Iniciação Científica CNPq/PIBIC

*** Bolsista Iniciação Científica CNPq

A pesquisa contou, ainda, com a participação de bolsistas (CNPq) na fase de levantamento de dados: Renata Rossi Tavares (I.C), Valéria de Almeida Pereira (A.P) e Anália Ribeiro Heck (A.T).
} 
Em trabalhos realizados pelo grupo de pesquisadores do núcleo em pesquisa em Ética em enfermagem, saúde mental e Educação/Escola de enfermagem de Ribeirão Preto da Universidade de São Paulo/Conselho Nacional de Desenvolvimento Científico e Tecnológico (NUPÉTICA - ENSAME/EERPUSP/CNPq) referente a projeto integrado de pesquisa sobre a evolução de assistência de enfermagem hospitalar nas últimas décadas, evidenciou-se que as décadas de 50 e 60 foram cenário de grandes e importantes transformações para a Enfermagem. Embora sem preparo adequado, a enfermeira dos anos 50 assumiu as atividades administrativas, desempenhando o papel de liderança da equipe de enfermagem e a de membro efetivo da equipe de saúde. Observou-se que no esforço em conciliar suas várias atribuições, a enfermeira delegou algumas de suas atividades a seus subordinados, procurando não se afastar totalmente do cuidado direto ao paciente. Embora sem nenhuma autonomia lutou para manter seu espaço, conquistando o respeito e o reconhecimento por sua competência e facilidade de adaptação às transformações tecnológicas. Destacase nesta década a importância dos valore éticos da profissão e a adoção do código de ética, bem como seus reflexos na formação destes profissionais (Vietta et. al., 1995).

A década de 60 deu continuidade a mudança relevantes na evolução da assistência hospitalar. Há nesta década uma preocupação com os temas pertinentes à profissão, à legislação específica, bem como às associações representativas da classe. Abre-se também um espaço às reivindicações e às interpelações populares (Germano, 1983).

Esta década caracterizou-se por um clima de transição havendo situações de superação de barreiras e dificuldades. Destaca-se ainda a ampliação do campo de ação do enfermeiro conquistado a partir do senso de responsabilidade acrítica, portanto embasado em atitudes de submissão às normas, rotinas e cumprimentos de ordens.

$\mathrm{Na}$ verdade, esta submissão foi o requisito da ideologia da enfermagem antiga que, desde sua origem em particular a de ANA NERI para os brasileiros, teve o significado de abnegação e dedicação. Isso marcou profundamente a profissão de enfermagem, tendo como slogan que "o enfermeiro têm que ser disciplinado e obediente".

Nesta década, portanto, a hierarquia foi respeitada com vigor e a enfermeira portou-se de forma submissa aos médicos cumprindo e obedecendo a ordem de seus superiores (VIETTA et. al., 1995).

A enfermeira buscou desenvolver suas habilidades administrativas assumindo a liderança do cuidado de enfermagem.

Destaca-se também na década de 60, uma preocupação de aspecto ético salientando o estabelecimento dos três princípios considerando fundamentais para a postura do profissional: respeito à natureza humana; relação do homem para com o seu semelhante e direção vertical a Deus (TURKIEWICZ, 1965).

É na década de 60 que pela primeira vez, determina-se um currículo mínimo 
para o ensino das carreiras universitárias no Brasil e entre elas, inclui-se a Enfermagem. O Conselho Federal de Educação, em 1962 fixou em três anos o currículo mínimo do Curso de Graduação em Enfermagem (BRASIL. Leis, 1962). Este negligenciou a importância da inclusão de disciplinas de cultura geral ou de estudos de humanidades (ALCÂNTARA, 1964), permanecendo excluído o ensino de Saúde Pública. O parecer 271/62 do Conselho Federal de Educação (CFE) dirige o enfoque sobre as clínicas especializadas de caráter curativo e o predomínio no ensino para entender o mercado de trabalho, ou seja, o hospitalar (SILVA et al., 1979).

Em decorrência desta situação, surgem movimentos para a inclusão do ensino de Saúde Pública, Ciências Sociais e do Comportamento, visando desenvolver nos estudantes uma visão do indivíduo como um ser bio-psico-social.

$\mathrm{Na}$ década de 60, destaca-se ainda a Lei Orgânica da Previdência Social, primeiro passo para a unificação previdenciária que se verificou em 1966.

A rede de hospitais e ambulatórios passou a ser insuficiente para atender à demanda, passando então o Instituto de Previdência Social (INPS) a ser o grande "comprador" de serviços do setor privado.

Neste período a situação econômica financeira do País sofre grave crise, surgindo a preocupação pela racionalidade dos gastos com a saúde.

Os movimentos perduraram visando a melhoria do ensino e da prática adentrando a década seguinte ante-projetos curriculares que deram origem ao parecer 163/72 surgindo por força da lei 5.540/68 referente à reforma universitária (BRASIL. Leis, 1972).

Segundo OLIVEIRA, 1981, o relator da matéria acima referida, incorporando as sugestões da Associação Brasileira de Enfermagem (ABEn), reconhece a complexidade crescente das atividades de enfermagem e a necessidade de três níveis de ensino (enfermeiro, técnico e auxiliar de enfermagem). Assim, o enfermeiro deveria exercer as atividades mais elevadas relativas à enfermagem, na forma requerida, pelo meio brasileiro. O currículo deve fornecer ao profissional um conhecimento científico que lhe permita não somente executar as técnicas atuais mais avançadas, como acompanhar a evolução que estas tendem a sofrer, inevitavelmente, em razão da evolução científica. Deveria, além disso, dar base suficiente ao graduado para acesso, através de cursos de pós graduação, à docência em nível superior à participação na pesquisa.

A partir de então, as enfermeiras começaram a compreender que a prática do exercício só alcançaria a fase de maturidade com o desenvolvimento da pesquisa em enfermagem. As líderes, sobre tudo as docentes, passaram a se conscientizar de que somente através de procedimentos sistematizados e o uso de metodologia científica é que se chegaria a equacionar com objetividades e rigor os problemas e as áreas a serem trabalhadas (OLIVEIRA, 1963).

No início da década de 70 , o sistema de saúde, que parecia manter coerência com seus determinantes estruturais começa a viver "crise" onde o modelo de desenvolvimento até então prevalente, passa a ser contestado nos seus 
componentes econômicos, políticos e sociais. A principal modalidade da prática e organização de saúde é a medicina hospitalar, com tendência à concentração e especialização de recursos e reconhecimento; a crise do sistema ganha intensidade e, em 1974, provocam um clima de tenções e acentuada piora das condições de saúde do povo brasileiro. Surgiram nesta, época, inúmeras propostas visando superar o impasse e a adequação do sistema de saúde às suas novas responsabilidades passam a ser objeto de preocupação do governo federal, dando origem à reforma do setor de saúde. O que acontecia aqui refletia a situação da América Latina. Daí as preocupações da Organização Panamericana da Saúde (OPS) e Organização Mundial da Saúde (OMS) na determinação de políticas de extensões de cobertura dos programas traduzidas pela simplificação, interiorização e promoção comunitária.

A década de 70 continuou a ser palco das grandes mudanças na educação, que teve seu início na década de $60 \mathrm{com}$ a Reforma Universitária a qual pretendeu dar um novo cunho ao ensino universitário no Brasil.

O parecer 162/72 acresce ao ensino profissionalizante e das ciências biológicas o ensino da sociologia e psicologia, porém com uma listagem de disciplina que favorece o ensino daquelas em detrimento destas.

Mantendo a exclusão do ensino de enfermagem de saúde pública do tronco profissional comum, o parecer 163/72 favorece a formação do enfermeiro para o atendimento à uma assistência sofisticada, de casos raros, o que atende o mercado de trabalho e a política preconizada pelo ministério da previdência social. Em contra partida o ministério da saúde empenhava-se numa nova visão política preventivista, de regionalização e simplificação das ações de saúde (SILVA et al., 1979).

Na década de 70 , foram intensificadas as políticas de extensão de cobertura através do plano decenal de saúde para as Américas, 1972 e da conferência internacional de Alma - Ata - URSS, 1978.

A partir daí, então, novos conceitos e metas governamentais no setor saúde foram lançados para o mundo, entendendo saúde como um direito humano afastado de qualquer discriminação social ou econômica. A década de 70 foi caracterizada por intensas mobilizações da classe. A partir das mudanças de dominação da categoria, determinada pelo Ministério do Trabalho, contida no portaria $n^{\circ} 3.311 / 74$, foi aberto 0 caminho à sindicalização. Em 1972 foi criado o Conselho Federal (COFEN) e o Conselho Regional de Enfermagem (COREN) conforme lei $\mathrm{n}^{\circ}$ 5.905-73 (entidades disciplinadoras do exército profissional, uma autarquia vinculada ao Ministério do Trabalho) (BRASIL. Leis, 1976).

Em 1975 foi fundada a Associação Brasileira de Educação em Enfermagem (ABEn), cuja finalidade é o desenvolvimento da educação na enfermagem no País.

A seguir em 1976 surgiu a Primeira Associação Profissional a requerer a carta sindical no município do Rio de Janeiro. Entretanto, o primeiro sindicato de enfermeiro a ser criado foi o do Rio Grande do Sul.

Ainda, na década de 70 as líderes de enfermagem do País, através do Conselho Federal de Enfermagem (COFEN), propuseram um anteprojeto de lei do 
exercício profissional em substituição à lei no 2604/55 que incluísse "um conjunto de disposições que não só verticalizasse o exercício da enfermagem distinguindo a hierarquizando profissões e ocupações, como também estabelecessem, mas instituições de saúde, condições estruturais imprescindíveis a esse exercício".

Houve nesta década, também, um avanço intensivo na ciência e tecnologia. Segundo PONTES (1970): "os contínuos e complexos progressos da ciência e da tecnologia refletem na prática de enfermagem produzindo alterações relevantes na organização e operacionalização dos serviços". A análise da situação, segundo o grupo de trabalho da Organização Panamericana de Saúde (OPS) 1978, revelou o seguinte panorama: o crescimento institucional, em número e tamanho, particularmente com início da previdência social e ampliação dos recursos humanos necessários à prática curativa, exigiu maior dedicação da enfermeira para atividades administrativas o que a distanciou do contato contínuo e direto com o paciente. O deslocamento da enfermagem para atos mais administrativos foi reforçado por uma preferência da enfermeira por uma atividade de reconhecimento intelectual, com melhores oportunidades de exercer sua autoridade e ações de comando. As decisões burocráticas dos níveis centrais do sistema institucional favoreceram esta tendência no momento de estruturar os quadros funcionais e correspondentes escalas salariais, já que para acender na organização era preciso trocar a assistência direta ao paciente por cargos de natureza administrativa. Essa posição da enfermeira acelerou o aparecimento de pessoal auxiliar de Enfermagem com preparo de 11 meses e requisito mínimo do $1^{\circ}$ ciclo secundário, para trabalhar com menor nível salarial.

CARVALHO \& CASTRO (1979), detectaram problemas nesta nova perspectiva. Consideraram que a enfermeira estando presa a cargos administrativos, cada vez mais afastada das atividades características, perdera progressivamente sua autonomia diante da equipe de saúde. Ressaltaram ainda a repercussão disso para a imagem da enfermeira que na sociedade brasileira permanece distorcida, já que essa imagem configura-se a partir do reconhecimento do valor dos serviços prestados diretamente ao paciente.

Desde a década de 60, as enfermeiras americanas buscavam caminhos que pudessem elevar a profissão ao conceito de ciência através da construção de um corpo de conhecimentos específicos elaborando marcos conceituais e teorias de enfermagem.

A partir da década de 70 , as enfermeiras brasileiras reconhecendo a necessidade de um corpo de conhecimento, começaram a entrar em contato com as teorias de enfermagem que segundo SOUZA (1984) já vinham sendo desenvolvidas nos Estados Unidos desde a década de 60 tendo sido publicadas várias delas como as teorias de ORLANDO (1961); HALL (1966); LEVINE (1967). Em 1972, ORLANDO e LEVINE republicaram suas teorias de modo mais elaborado.

$\mathrm{Na}$ década de 70 surgiram inúmeras outras teorias entre elas a de ROGERS (1970); OREM (1971); KING (1971); LEININGER (1978) citados por DANIEL (1978) e ROY (1976); NEWMAN (1979). 
No Brasil, a primeira teoria de enfermagem foi a de WANDA HORTA fundamentada na teoria das necessidades humanas de MASLOW apresentada no XXI Congresso Brasileiro de Enfermagem em São Paulo. Esta foi a primeira teoria de enfermagem brasileira a se impor como base para o cuidado sistematizado da assistência de enfermagem. Com isso a enfermagem passa a utilizar-se da metodologia científica na assistência de enfermagem. Posteriormente outros trabalhos foram elaborados surgindo modelos de assistência entre eles os de PAIM (1974) e VIETTA (1985) citados por DANIEL (1987). A cada um fundamentado nos mesmos supostos básicos do método científico tradicional, mas operacionalizado, segundo visões filosóficas e técnicas diversas.

Em relação ao ensino e ao saber em enfermagem surgiram, nesta década, dois fatos importantes conseqüentes da Reforma Universitária: a modificação do currículo de Enfermagem pelo aparecer 163/72 do Conselho Federal de Educação (CFE) que criava as habilitações em Enfermagem de Saúde Pública, Obstetrícia e Ginecologia e Médico-Cirúrgica a o segundo, a criação da pós-graduação "stricto sensu" em enfermagem. Esta teve início já em 1972 com a implantação do curso de mestrado na escola Ana Neri, da Universidade Federal do Rio de Janeiro. Em 1973, iniciou-se o segundo curso de mestrado, na Escola de Enfermagem na USP seguido, em 1973, pelo primeiro mestrado em psiquiatria da Escola de Enfermagem de Ribeirão Preto Universidade de São Paulo.

Ainda nesta década, foram implantados os primeiros cursos de mestrado do Departamento de Enfermagem da Universidade Federal da Paraíba e da Escola de Enfermagem de Ribeirão Preto - USP. No final da década ficou evidente o esforço orientado no sentido da qualificação dos docentes, um investimento nas atividades de pesquisa e na assistência, um empenho em estenderem-se às comunidades os programas de saúde.

Finalizando, entendemos que: o sentido que damos às coisas hoje está inevitavelmente ligado ao entendimento que temos do passado. A maneira como desempenhamos nosso papel na sociedade depende do ponto em que nos encontramos neste percurso e no diálogo que traçamos no passado e o presente. Reconhecendo a importância deste processo na recuperação de fatos e acontecimentos da história como quesito para a inserção na totalidade desta realidade e a garantia de podermos agir sobre ela, é que nos propomos a pesquisar a década em que questão estabelecendo como OBJETIVOS:

RESGATAR A EVOLUÇÃO DA ASSISTÊNCIA DE ENFERMAGEM HOSPITALAR NA DÉCADA DE 70; ANALISAR DEPOIMENTOS DE ENFERMEIROS REPRESENTANTES DA DÉCADA DE 70 OBTIDOS ATRAVÉS DA TÉCNICA DE ENTREVISTA ORAL; CONHECER A PERCEPÇÃO DA ENFERMAGEM ATUAL PELOS ENFERMEIROS DA DÉCADA DE 70. 


\section{METODOLOGIA}

Embora haja especificidades em termos de vivência em nível de região e tipo de hospital onde essas ocorreram (particular, estatal e de ensino), optou-se no presente estudo pela investigação em um hospital escola do interior paulista, limitando a população a 23 enfermeiros formados na década de 70 , em exercício neste hospital, presentes no período previamente marcado para a tomada de depoimentos.

Para tanto utilizou-se da técnica da história oral, cujo o termo amplo recobre uma quantidade de relatos a respeito de fatos não registrados por outro tipo de documentação, ou cuja documentação se queira complementar (QUEIRÓZ, 1988).

Colhido por meio de entrevista esta técnica registrada a experiência de um só indivíduo (enquanto representante de uma coletividade) ou de vários indivíduos da mesma coletividade.

A técnica utilizada envolveu a modalidade de depoimentos pessoais ou relato oral. Da vida do informante só interessaram os acontecimentos inseridos diretamente no contexto profissional ou na temática a ser focalizada, buscou-se obter do narrador o essencial, dispensando que era supérfluo e desnecessário à análise dos dados. O pesquisador teve sob seu controle o enfoque do depoimento através de roteiro, previamente elaborado, avaliado por três juízes e testado em plano piloto.

É importante ressaltar na técnica mesmo que o pesquisador venha registrar um número reduzido de depoimentos, seu objetivo é captar a idéia do grupo, a sociedade de que ele é parte. Busca, portanto, captar a coletividade a partir dos indivíduos. Não se trata de considerá-los isoladamente, nem de compreendê-los em sua individualidade, ao contrário, o que se pretende é captar, através de seus depoimentos o que se passa no interior da coletividade da qual participam ou são membros integrantes. Os sujeitos não são individualizados, são pessoas representativas, não sendo nem mesmo necessários nominá-los.

\section{PROCEDIMENTO}

Inicialmente foi dada aos sujeitos a liberdade para exporem suas vivências, através de relato livre, a partir de duas questões norteadoras: "COMO ERA A ENFERMAGEM NA DÉCADA DE 70?", "COMO É OU ESTÁ A ENFERMAGEM HOJE?". Após o relato foi oferecido ao enfermeiro um roteiro a ser consultado para complementação de seu depoimento, cujos objetivos foram 
tentar uma maior abrangência da temática e homogeneização do conteúdo dos vinte e três depoimentos. Segundo a preferência dos sujeitos, o relato oral foi obtido através da técnica do gravador em local e tempo determinado. Após as entrevistas o material foi imediatamente transcrito e posteriormente categorizado segundo as etapas do Modelo de GIORGI (1985) adaptado por VIETTA et al. (1995).

Este procedimento propiciou uma retomada no contato com o conteúdo dos depoimentos, favorecendo uma análise em maior profundidade.

Para isso, seguiram-se os seguintes passos:

- Leitura atenta e cuidadosa do conteúdo total dos depoimentos com vistas à apreensão do seu significado em sua estrutura global.

- Releitura de cada um dos depoimentos e procedimento de cortes nos relatos, tendo por base, em primeiro lugar, temas mais amplos e, em seguida, temas específicos, relevantes para a compreensão e análise da temática em questão.

- Agrupamento destes recortes em categorias visando a identificação de pontos comuns entre os depoimentos na ordem dos questionamentos de maior inquietação.

- Finalmente, a análise destes agrupamentos tendo em vista o objetivo maior: o resgate da evolução da assistência de enfermagem e sua atuação na década de 70 .

\section{ANÁLISE E COMENTÁRIOS DOS DEPOIMENTOS}

Os depoimentos obtidos reforçam os achados na literatura especializada, mostrando a década de 70 como um período de profundas e intensas mudanças. Tal característica se mostra evidente na medida em que os relatos obtidos dos representantes do início da década revelam em certos aspectos, incoerentes e, às vezes, até contraditórios, com os obtidos dos representantes do período intermediário e do final da década em questão.

Desse modo, representantes do início da década relatam que o curso de graduação preparava teórica e tecnicamente o aluno para a profissão e que isto se devia, aos seguintes fatos: do ensino estar voltado para o como de trabalho; ao bom entrosamento existente entre docentes e enfermeiros de campo, a carga horária e os esquemas de estágios e a realização de estudos de casos desenvolvidos como um exercício para o aprendizado clínico. Este preparo, segundo estes entrevistados, davaIhes o preparo básico que era posteriormente complementado com a experiência adquirida no exercício profissional.

“... a formação no meu tempo era boa, estava voltada para o campo prático e havia um bom entrosamento entre docentes e o pessoal de campo". 
“... a escola me deu subsídios para exercer a profissão, aproveitei muito os estágios, me preparei para o cuidado direto ao paciente e para administrar".

“... o preparo começava já no transcorrer da graduação e no esquema rígido dos estágios com períodos, inclusive noturno e vespertino, o que dava uma real visão da prática profissional nas 24 horas".

“... com alunos assumíamos de fato a responsabilidade e fazíamos todas as atividades inerentes à profissão, atendimentos, vacinas, préconsultas, não havendo limitações de funções".

“... os estudos de caso nos levavam ao aprofundamento de conhecimentos sobre a doença, o paciente, os fatores psicológicos, etc; isto nos dava uma bagagem muito grande".

Por outro lado os relatos obtidos dos representantes do período intermediário e do final da década em questão afirmam que:

“... minha formação em administração foi muito falha e eu tive muitas dificuldades no campo de trabalho".

“... a escola me deu a base, mas eu tive muitas dificuldades e me sentia muito despreparada. Apesar disto, eu tinha muito bem definido o meu papel profissional".

Em considerações aos tempos atuais, os representantes da década fazem a seguinte relação:

“... a escola estava mais presente no hospital. $O$ aluno era preparado de modo diferente e dava menos trabalho que os de hoje, era mais responsável e se envolvia mais com o cuidado integral do doente".

“... hoje as coisas não são mais como antigamente e o conhecimento não é mais profundo".

“... hoje a Escola de Enfermagem está cada vez mais se desvinculando do hospital, hoje é raro o aluno vir para o campo de trabalho e quando vem é sem a devida supervisão e envolvimento com o trabalho ou com o paciente".

“... o relacionamento escola-hospital hoje é muito fora da realidade".

“... eu fico chateada com a postura atual da escola, pois ela tem o Hospital, um argumento ótimo, um campo de trabalho excelente e não valoriza ou reconhece. Na minha época de estudante eu cheirava $\mathrm{HC}$, dormia HC, etc".

“... esse negócio da escola ter ficado bonita, a salinha de treinamento (laboratório), o distanciamento do hospital, tudo ficou muito estanque, frio, impessoal e a escola e a profissão perderam muito. A escola partiu para outro extremo. A pesquisa está atrofiada e a experiência de campo está ficando de lado".

Os sujeitos lamentam esta situação de distanciamento e enfraquecimento de vínculo entre o hospital e a escola e tecem considerações muito importantes sobre as perdas e suas conseqüências para a profissão.

"... é uma pena o afastamento escola/hospital, a coisa fica muito em torno de disputas pessoais envolvendo o poder e isso acaba com a profissão". 
“... quando se divide, se subtrai, a escola fica sem o campo adequado para o aprendizado do aluno e o campo cada vez mais inadequado não absorve o produto que é formado pela escola... o profissional recémformado não se identifica com o hospital, nem quer trabalha lá".

“... e a visão fica deformada, existe um fantasma nesse relacionamento que precisa ser desmistificado com urgência. É um time contra o outro. E nos dois lados existem profissionais, muito bons que não estão sabendo se integrarem".

Não obstante estas queixas, os sujeitos representantes no final da década parecem reconhecer que nos últimos anos houve por parte de docentes, alguma iniciativa no sentido de sanar esta problemática mostrando através de um exemplo caminhos e possibilidades conforme mostra o depoimento, referente à realidade atual.

“... de dois anos para cá, a escola, na minha área, trazido alunos para estágios. Esse estágio tem sido programado, as professoras ficam com os alunos, e parece que o entrosamento melhorou. $O$ aluno tem entrado no esquema da clínica como elemento da equipe e isso é muito bom, porque o pessoal de campo sente que não está apenas dando sua contribuição, mas recebendo também. Não tem a questão do docente vir avisar que vai ter alunos. Existe um entrosamento, uma troca de experiência. Os professores e os alunos assumem o paciente junto com o pessoal da clínica. Nós temos conseguido nos entender. Se o aluno precisa sair, o pessoal da clínica assume, se o pessoal da clínica tem uma reunião ou outra circunstância que precise se ausentar o pessoal da escola assume, então não há quebra no atendimento e acho que isto é muito bom para o aluno e para o paciente".

Corroborando com este aspecto LUGO (1979), comentando sobre a integração docente assistencial diz: em relação à formação de estudante e à prestação de cuidados a pacientes esta não alcançou ainda um estado satisfatório de harmonia e equilíbrio. Pronunciando-se sobre a separação entre o ensino e serviço, a autora considera não muito feliz o ambiente existente entre docentes e enfermeiras de serviço e crê que ambos os grupos perderam status. A enfermeira perdeu a autoridade em relação ao paciente, e a professora perdera autoridade sobre o estudante. A enfermeira de serviço crê que perdeu o recurso do estudante para o cuidado do paciente, e se considera como vítima do pessoal do ensino. A docente, que tinha liberdade para usar o cenário clínico como laboratório para aprendizagem do aluno, agora se sente como visitante, em certas ocasiões até inoportuno, e com muitas limitações para atuar. Por outro lado, a prioridade e preferência dadas aos docentes pêlos cursos de pósgraduação para fazer frente às exigências acadêmicas, provocou um certo malestar no pessoal de serviço que, não tendo esta preparação, sente se relegado a um segundo plano (CARVALHO \& CASTRO, 1979).

Um fator importante que surge, nesta década mais precisamente no ano de 1976, no contexto do hospital-escola estudado, é o fato de a escola ter aumentado o número de vagas para o curso de graduação. 
“... minha turma foi a primeira turma de 80 alunos, éramos muitos e não tínhamos muito ensino direto, o ensino ficou meio massificado".

“... a partir da década de 70 os grupos de alunos começaram a aumentar, as turmas cresciam de ano para ano".

“... aquela coisa de estar próximo do aluno, de conhecê-lo, não aconteceu na minha turma, tudo ficou muito diluído, era um grupo heterogêneo".

De certa forma percebe-se, da parte dos sujeitos, uma certa consciência de que a Escola oferece a base suficiente para o exército inicial da profissão, mas, que o preparo vem com a prática após a formatura.

“... a escola me deu a base necessária ao exercício profissional, ela não pode dar mais do que me deu, porque a gente aprende mesmo é trabalhando e no dia a dia".

"... eu sofri muito, mas pouco a pouco fui aprendendo, com os pacientes, com os outros funcionários e acabei me encantando com o meu trabalho".

"... não adianta o aluno ficar aflito porque a escola não ensinou isto ou aquilo, eu também não sei muita coisa e sou formada há quase 20 anos".

“... hoje eu acho que esse período que trabalhei no centro cirúrgico foi muito bom para o meu desenvolvimento profissional, porque a formação que eu tive na escola foi falha".

“... eu acho que a escola não forma o aluno completamente, muita coisa deixa a desejar...".

“... meu curso de enfermagem foi dentro de minhas expectativas, se bem que eu acho que havia uma rigidez muito grande e a preocupação era a de que saíssemos bons profissionais, mas eu sinto que saí como um bom estudante".

"... o enfermeiro era melhor preparado e tinha maior competência".

"... hoje o profissional recém-formado chega inseguro, não mostra habilidade técnica e se sente perdido".

Vale a pena ressaltar que este sentimento de insegurança expresso pêlos sujeitos, não parece ser exclusividade desta profissão, sendo queixa comum, também, em outras profissões, agravado na enfermagem pela natureza humana de seu objeto material, ou seja, o homem e particularmente de seu objeto formal, o cuidado integral do ser.

A escola segundo os entrevistados oferecia os conhecimentos básicos suficientes para garantir bom desempenho de recém-formado num período relativamente curto de experiência prática.

“... quando saímos da escola em pouco tempo éramos capazes de tocar uma clínica... aprendíamos todas as técnicas rapidamente e passávamos o plantão com muita segurança e responsabilidade".

“... quando eu me formei não me sentia completamente segura e preparada, mas eu me senti muito apoiada e supervisionada pela chefia e rapidamente adquiri experiência e segurança".

“... hoje já se espera que o enfermeiro venha pronto e isso eu atribuo ao distanciamento escola-hospital". 
Segundo os depoimentos os sujeitos acreditam que, com o enfraquecimento do vínculo escola-hospital, o pessoal de campo foi perdendo a concepção do recémformado, como alguém que necessita complementar a sua formação na prática.

“... o pessoal do hospital está perdendo a visão do recém-formado como alguém que ainda precisa de apoio e supervisão".

Porém, os sujeitos não descartam, que de certa forma, este despreparo tenha outras causas, como por exemplo, o nível do ensino oferecido ainda hoje pelas escolas de enfermagem.

“... hoje o aluno se forma com menos conhecimento e experiência prática".

“... não sei dizer se a falha está só no ensino ou está no próprio pessoal que procura o curso ou ainda, se é dos dois".

Quanto à postura da enfermeira no contexto da profissão, da equipe e da instituição hospitalar, esta aparece nos depoimentos como algo que foi sendo deteriorado ao longo dos anos, com início a partir do final da década de 60 , com perda de status para este profissional.

“... na minha época a enfermeira era um elemento imprescindível para a equipe médica e para o restante do pessoal".

“... a presença da enfermeira era solicitada nas visitas médicas e somente iniciadas na presença desta".

“... o enfermeiro era a peça mais importante para o estabelecimento de condutas, havendo melhor relacionamento com a equipe médica. Apesar de trabalharem separados, o médico respeitava a enfermeira e a via como um profissional que o complementava".

No entanto fica claro pelos relatos que toda esta perspectiva foi desenvolvida sob uma imagem tradicional e disciplinar rígida.

“... nós enfermeiras tínhamos uma moral rígida, usávamos uniformes padronizados em modelos apropriados que eram observados com rigor, inclusive no comprimento, cabelos presos; unhas curtas de preferência sem esmalte; jóias nem pensar; baton super discreto e apenas atitudes profissionais com a equipe médica".

“... vínhamos com a roupa de casa e o uniforme permanecia no armário. Não se andava com uniforme nas ruas. Era proibido se sentar nas camas dos pacientes. Normas e rotinas eram cumpridas ao pé da letra".

A postura era adotada tendo como modelo as enfermeiras mais antigas e experientes. Essas profissionais eram tomadas como exemplo pelas profissionais recém-formadas.

“... quando me formei, acho que a enfermagem no hospital tinha modelo a ser seguido".

“... eu me lembro de quando eu me formei e comecei a trabalhar, a divisão de enfermagem tinha as diretoras que em sua quase totalidade eram modelos de profissionais que a gente almejava ser igual no futuro, elas eram 
realmente o espelho no qual nos víamos quando tivéssemos adquirido a experiência necessária".

Referindo-se à situação atual os sujeitos expressam certo pessimismo quanto à postura dos atuais enfermeiros.

“... hoje os modelos são exceções, e muito poucos profissionais nos motivam a imitá-los".

Os sujeitos conjecturam que uma possível causa da deterioração da postura profissional na atualidade possa ser encontrada na própria enfermeira.

“... por culpa do profissional as coisas vão mudando e a própria divisão de enfermagem não tem conseguido manter o perfil de seus profissionais dentro de um padrão de conduta adequada ao bom desempenho profissional e mesmo uma posição dentro da equipe e da instituição".

Os depoimentos salientam as conseqüentes perdas de "status" e reconhecimento que atingiu a profissão.

“... por causa de sua postura a enfermeira hoje em dia tem o seu papel muito confundido com o do auxiliar e do técnico e só em casos muito particulares é que ela se destaca".

Ainda referindo-se à postura atual do profissional enfermeiro, assim se expressam os sujeitos:

“... hoje eu já não vejo a enfermeira como modelo, o pessoal que trabalha também foi perdendo seu "status", até porque o nível sócio-econômico e cultural do pessoal caiu muito, o português, a dificuldade de comunicação são evidentes e a própria enfermeira acabou se tornando uma trabalhadora igual, assalariada. Não há aquele respeito de maneira geral. Hoje, uma ou outra consegue se manter como um ponto de referência".

O relacionamento da enfermeira com a equipe médica e de enfermagem, parece ter sido, na década em estudo, segundo os depoimentos, uma fase de trocas e reciprocidades, calcado em bases mais humanas.

“... Naquele tempo o relacionamento com a equipe médica era muito bom”.

“... a enfermeira impunha com sua postura e competência os auxiliares e atendentes aceitavam a sua autoridade".

“... hoje o funcionário até esquece que a gente é enfermeira e acaba nos tratando bem em nível de igualdade, isso acontece porque a enfermeira não está sabendo se posicionar como coordenadora e líder da equipe".

“... eu acho que antigamente a comunicação era mais fácil. $O$ grupo era menor e o relacionamento muito mais estreito, por onde se passava ia se fazendo amigos... servidores que até hoje me encontram e me cumprimentam querendo saber onde estou".

“... éramos mais respeitados pelo grupo de auxiliares e atendentes... havia mais respeito entre os outros profissionais da mesma profissão e de outras profissões". 
Os sujeitos entrevistados supõem que um dos motivos desta transformação é o fato do despreparo dos profissionais tanto da equipe de enfermagem quanto da equipe médica, conforme segue:

“... hoje em dia cinto que o respeito entre médico, enfermeiros e de mais profissionais esta cada vez pior, acho que isto se deve ao fato do desemprego do enfermeiro que já não domina o seu saber".

“... mau preparo da equipe médica sobrecarrega o trabalho da enfermagem e provoca muitos desentendimentos".

“... a liderança da enfermagem está comprometida pelo despreparo, postura profissional e mesmo o vocabulário".

“... o enfermeiro da década atual não mostra segurança e tenta se impor pelo poder e não pelo saber... acho que melhor forma de liderar e posicionar é o saber fazendo... o enfermeiro não mostra, ele manda. Isso demonstra insegurança e despreparo. E a coisa vai aos trancos e barrancos".

Referindo-se ainda a cada década atual os sujeitos assim opinam:

“... com relação ao trabalho de equipe eu vejo o enfermeiro com maior dificuldade hoje, a equipe médica também está mais fraca de sabedoria".

“... antigamente havia um profissionalismo maior, hoje existe um coleguismo restrito e no momento que você precisa ser extremamente profissional você não é compreendida".

“... eu acho que o enfermeiro precisa retomar urgentemente sua postura profissional".

Pelos depoimentos depreendi-se que, no final da década de 70 , a ética já não era matéria considerada importante e fundamental na formação do enfermeiro. Havia outras preocupações mais urgentes como, por exemplo, o enfoque político e ideológico. Tiveram início os movimentos de reivindicação por maiores salários e melhores condições de trabalho.

“... os valores éticos e morais não foram muito valorizados durante o curso nesta década, o restringindo-se mais ao enfoque teórico filosófico".

“... o salário era uma preocupação e se brigava e reivindicava melhores condições de trabalho".

No entanto estas lutas parece não ter sustido o efeito desejado, não garantindo a manutenção de vantagens conquistadas, nem mesmo o empenho em continuar luta.

“... hoje o enfermeiro está acomodado, não há mobilização por melhores salários".

“... naquela época a classe era mais unida e participávamos de reuniões onde sempre surgia um líder".

“... na minha unidade perdi várias enfermeiras que pediram demissão chorando por causa de salário".

“... hoje a classe não é unida... os médicos ditam as ordens... a enfermeira executa: a divisão de enfermagem não conhece seus profissionais... com isso a 
classe dentro do hospital vai gerando grupos isolados e muito corporativista".

Fica evidente nos relatos, a relação que os sujeitos fazem entre o salário, a valorização profissional e a postura de enfermeiro.

“... a questão salarial é uma questão muito forte e ajuda também na desvalorização profissional, mas eu acho que a ética recuperaria muito mais a valorização do enfermeiro".

“... hoje a má remuneração obriga a que a maior parte do pessoal de enfermagem faça jornada dupla de trabalho o que desgasta física $e$ psicologicamente o profissional".

“... gostaria de acreditar que se a remuneração fosse melhor e mais adequada o padrão de serviço melhoraria, não acredito... para mudar talvez fosse necessário mudar os valores, os objetivos e a postura".

Este último relato e outros tantos relacionados à ética, mostram a preocupação do profissional em relação a este valor. Há mesmo uma conotação de desvalor da profissão.

“... a parte ética da profissão tem me preocupado muito, a postura profissional é mesmo marcante, ele vem mal preparado técnica e moralmente".

“... as instituições também poderiam fazer um trabalho melhor na recuperação ética. A questão valorização é importante na revisão salarial. 0 intercâmbio escola-hospital é imprescindível também para o adequado posicionamento ético e moral e na conquista de melhores salários e melhor condições de trabalho".

“... hoje os níveis salariais, as condições de trabalho e a falta de reconhecimento tem provocado a evasão do profissional no mercado de trabalho, muitos pensam em deixar a profissão e há uma onda de pessimismo entre os profissionais que estão na ativa. Fatores de ordem política e social tem contribuído para a atual situação da enfermagem, mas constata-se também a inadaptação do profissional, a falta de profissionalismo e a insegurança em assumir um emprego em tais circunstâncias".

“... do jeito que estão caminhando as coisas é melhor deixar a enfermagem e procurar outra profissão".

“... as condições atuais de trabalho me deixam insegura, a responsabilidade é muito grande e a instituição não dá nem condições nem apoio".

Porém, tudo isso parece não justificar para o enfermeiro seu desprestígio social nem a má qualidade da assistência de enfermagem.

“... temos que admitir que não podemos deixar de sentir as dificuldades financeiras que agravam a cada dia. Porém, acredito que esta dificuldade não justifica a má qualidade de assistência oferecida, o deixar de fazer o melhor que se pode, mas o que se constata é um desânimo total".

Aqui aparecem também críticas severas dos entrevistados em relação à omissão ou pouca atuação dos órgãos de classe. 
“... o pessoal está com o menor salário dos últimos 20 anos. O COREN vem cobrando suas anuidades maiores do que os conselhos de outras profissões e nada faz para a melhoria das condições do enfermeiro".

Pelo exposto, percebe-se a insatisfação geral da classe que com os baixos salários que recebe, se você obrigada a manter dois a três empregos, o que leva a profissão a decair em qualidade além do desgaste físico e mental do enfermeiro.

Com isso, a má remuneração, a falta de estímulo, o desgaste físico e emocional, a não perspectiva de melhoria das condições de trabalho, a indiferença dos órgãos de classe parecem ser os fatores geradores de insatisfação geral.

“... a política de saúde do país não valoriza o profissional enfermeiro, os órgãos de classe (ABEn, COFEN e COREN) não se manifestam de forma efetiva frente à situação do profissional. Não há mobilização da classe, o hospital não tem interesse em investir no profissional, há uma alienação dos enfermeiros frente a esta situação".

“... o enfermeiro precisa se virar para sobreviver e acaba tendo que assumir mais de um emprego".

\section{CONSIDERAÇÕES FINAIS}

Os depoimentos confirmaram e em certo sentido, completaram os achados da literatura especializada revelando como característica da década de 70 um período de inovação e mobilização política.

$\mathrm{Na}$ opinião dos sujeitos, as Escolas de Enfermagem da época preparavam teórica e tecnicamente o aluno oferecendo-lhe o preparo básico para o exercício da profissão que era complementado posteriormente com a experiência prática.

O ensino estava voltado para o campo de trabalho e era facilitado pelo bom entrosamento existente entre docentes e enfermeiros do serviço, pela carga horária e esquema de estágios e, ainda, pela elaboração de estudos de casos.

Os sujeitos opinam que o enfermeiro da década em questão era melhor preparado do que o atual e tinha maior competência. Suas experiências revelam que o enfermeiro recém-formado chega inseguro, não mostra habilidades técnicas e se sente perdido.

Em relação ao relacionamento da enfermeira com a equipe médica e de enfermagem, os sujeitos consideram ter sido um período de trocas e reciprocidades estabelecidas em base mais humanas. Sentiam-se respeitadas em suas opiniões e reconhecidas em seus conhecimentos. Havia um relacionamento mais estreito e amigo. Neste aspecto sentem muitas diferenças entre a década de 70 e hoje, considerando que o relacionamento entre os profissionais é mais impessoal e o respeito já não é o mesmo. Acreditam que tal dificuldade tem muito haver com o 
despreparo do enfermeiro que não tem mais tanto domínio do saber. Sentem ainda uma falta de união da classe.

No que diz respeito à ética, os sujeito evidenciam em suas falas que, na década de 70, a ética deixou de ser uma matéria de importância fundamental, dando-se a ela uma conotação mais filosófica e menos aplicada. A isso os sujeitos atribuem o fato de haver outras preocupações mais emergentes como, por exemplo, o enfoque político e ideológico, as lutas por melhores condições de trabalho e melhores salários. Este fato, segundo a opinião dos sujeitos, tem ainda seus reflexos na prática atual.

Fica claro, nos depoimentos, ter havido uma certa deterioração da postura profissional do enfermeiro no contexto da equipe de saúde com conseqüente perda de status para este profissional.

Os sujeitos consideram também que toda esta trajetória foi desenvolvida sob uma imagem tradicional e disciplinar do profissional, sobretudo de uma visão moral rígida. Havia muito rigor e controle da conduta do enfermeiro. Enquanto na atualidade, a postura manifesta-se através do desinteresse e descompromisso com o trabalho.

Os sujeitos consideram também que, nas décadas posteriores, os enfermeiros têm vivido situações que propiciam o descompromisso, relacionadoas à condições de baixa remuneração, falta de reconhecimento profissional, escolha profissional inadequada, desinteresse pelo trabalho e despreparo acadêmico entre outros.

No entanto, evidencia-se que a década de 70 foi uma época na qual a profissão foi absorvida por um número crescente de jovens. A demanda era grande, porém, iniciava-se um processo de evasão do profissional o mercado de trabalho. Em relação à enfermagem atual, os sujeitos informam sentir uma onda atual de pessimismo e atribuem esta situação a fatores de ordem política e social, inadaptação do profissional e insegurança em assumir um emprego nas atuais condições de trabalho, além da falta de apoio por parte das instituições de classe.

Os sujeitos são unânimes em afirmar que as dificuldades aqui mencionadas, não justificam a má qualidade de assistência oferecida pelos profissionais da área.

Finalmente, os sujeitos representantes da década de 70 , fazem críticas severas dirigida aos órgãos de classe, afirmando que o salário do pessoal de enfermagem é o menor dos últimos 20 anos e que o Conselho Regional de Enfermagem (COREN), pouco faz para a melhoria das condições do enfermeiro.

\section{CONCLUSÕES}

A década de 70 foi um período de transição da profissão com uma perspectiva não muito alentadora para as décadas precedentes. As mudanças ocorridas na década não surtiram os efeitos desejados, não contribuindo para elevar 
o padrão da classe. Na visão dos sujeitos da década de 70 , o que se conquistou em termos políticos não teve o desfecho e reflexo esperado, como no exemplo das lutas e reivindicações por melhores salários. O que se apreende na década de 70 é, sobretudo um sentimento de que a profissão é desprestigiada, sofrida e desamparada pelos seus próprios órgãos de classe, governos e instituições. Embora seja esta uma visão "pessimista", traduz de forma criteriosa e científica a linguagem comum da população estudada, excedida, talvez por conta da própria técnica que facilita e propicia aos sujeitos a oportunidade de extravasarem suas emoções, refletindo dessa forma, uma conotação de desabafo.

\section{NURSING EVOLUTION AT UNIVERSITY HOSPITALS: DECLARATIONS OF NURSES WHO WORKED IN THE 1970s}

This study is part of a more extensive project that proposes to recover significant aspects related to nursing care evolution from 1950s. This study is developed through the technique of oral declaration by active and retired registered nurses, in the context of an university-hospital from São Paulo State. The present study emphasizes the outcomes referring to the 1970s. As result becomes evident the undertaken effort by nurses in the struggle for profession's recognition and prestige; intense and deep transformations related to nurse's new roles as leadership of nursing staff and member of medical team.

UNITERMS: nursing, nursing care evolution, university hospital

\section{EVOLUCIÓN DE LA ENFERMERÍA EN EL CONTEXTO DE HOSPITAL-ESCUELA: DECLARACIONES DE ENFERMEROS DE LA DÉCADA DE 70}

Este estudio es parte de un proyecto más amplio intentando la captación de aspectos significativos relacionados a la evaluación de la asistencia de enfermería en las décadas de 50 a 90. La captación se ha realizado a través de la técnica de declaraciones orales de los enfermeros en ejercicio de la profesión, en el contexto de un hospital-escuela de interior del Estado de São Paulo. El presente estudio particulariza los resultados obtenidos, referentes a la década de 70. Como resultados se evidencian el esfuerzo imprimido por las enfermeras en la lucha por el reconocimiento y prestigio de la profesión. Las transformaciones intensas y profundas relacionadas a los nuevos roles de la enfermera como líder de los trabajadores de enfermería y miembro del grupo de la salud.

TÉRMINOS CLAVES: enfermería, evaluación de la asistencia de enfermería, hospitalescuela 


\section{REFERÊNCIAS BIBLIOGRÁFICAS}

01. ALCÂNTARA, G. Formação e aperfeiçoamento da enfermagem em face das exigências modernas. Rev.Bras.Enfermagem. v. 17, n. 6, p. 408-419, dez. 1964.

02. BRASIL. Leis et. Parecer n.163/72 de 28 de janeiro de 1972. Currículo mínimo dos Cursos de Enfermagem e Obstetrícia. Domumenta, fevereiro 1972. n. 135.

03. BRASIL. Leis etc. Lei n.5905 de 12 de julho de 1976. Rev.Bras.Enfermagem, v. 28, p. 88-98, 1976.

04. BRASIL. Leis etc. Parecer n. 271/62 de 19 de outubro 1962. Currículo Mínimo do Curso de Enfermagem à disciplina de Saúde Pública. Associação Brasileira de Enfermagem, Brasília, 1926-1976. p.158-160

05. CARVALHO, V.; CASTRO, I.B. Reflexões sobre a partida da enfermagem. In: CONGRESSO BRASILEIRO DE ENFERMAGEM, 31, Fortaleza, 1979. Anais. Fortaleza-CE: ABEn, 5 a 11 de agosto de 1979.

06. DANIEL, L.F. Enfermagem: modelo e processos de trabalho. São Paulo: Editora Pedagógica e Universitária, 1987.

07. GERMANO, R.M. Educação e ideologia da enfermagem no Brasil. São Paulo: Cortez, 1983.

08. GIORGI, A. Phenomenology and psychological research. Pittsburght: Duchisne, University, 1985.

09. HALL, L.E. Another view of nursing case and quality. In: STRAWB, K.M.; PARKER, K.S (Eds). Continuity of patient care: the role of nursing. Washington, D.C.: Catholic University Press, 1966.

10. LEVINE, M.E. The four conservation principles of nursing. Nurs.Forum, v. 6, n. 1, p. 45-50, january 1967.

11. LUGO, O.R. Enfermería y choque del futuro. In: $V$ CONGRESO DE LA FEDERACIÓN PANAMERICANA DE ENFERMERÍA, Porto Rico, 1979.

12. NEWMAN, M.A. Theory development in nursing. Philadelphie: F.A., Davis, 1979.

13. OLIVEIRA, M.I.R. de. Fases de crescimento e desenvolvimento Profissional. In: CONGRESSO NACIONAL DE ESTUDANTES DE ENFERMAGEM, 1, Bahia, out/1963. Anais. Bahia: ABEn, 1963.

14. . O enfermeiro e a enfermagem. In: CONGRESSO BRASILEIRO DE ENFERMAGEM, 33, Manaus, 1981. Anais. Manaus: ABEn, 2 a 7 de agosto de 1981.

15. ORLANDO, I.J. The dynamic nurse-patient relationship: function, process and principles. New York: Putnam's Sons, 1961. 
16. PONTES, C. et al. Formação do pessoal de enfermagem. Rev.Bras.Enfermagem, v. 22, no 1/2, p. 6-18, janeiro/julho 1970.

17. QUEIROZ, M.I. Relatos orais: do indizível ao dizível". In: VON SIMSON, O.M. (Org.). Experimentos com história de vida: Itália-Brasil. São Paulo: Vértice, 1988, p.14-43.

18. ROY, Sr.C. Introduction to nursing: an adaptation model. New Jersey: Englewood Cleffs, 1976.

19. SILVA, A.L.C.; BARROS, S.M.P. de; VIEIRA, T.T. Marco conceitual e estrutural dos currículos dos cursos de graduação em enfermagem. In: CONGRESSO BRASILEIRO DE ENFERMAGEM, 31, Fortaleza, 1979. Anais. Fortaleza-CE: ABEn, 5 a 11 de agosto de 1979. p.108-114.

20. SOUZA, M.F. de. O surgimento e a evolução histórica das teorias de enfermagem. In: SEMINÁRIO NACIONAL DE PESQUISA ENFERMAGEM, 3, Florianópolis. Anais. Florianópolis, 1984. p. 230-248.

21. TURKEWICZ, O. O primado do espírito na profissão. Rev.Bras.Enfermagem,v.18, n. 4, p.306, 1965.

22. VIETTA, E.P.; MAGALHÃES, M.F.; BUENO, L.V.; HECK, A.R. Tomada de depoimentos pessoal de enfermeiras hospitalares da década de 50 subsídios para a compreensão da enfermagem atual. Rev.latino-am.enfermagem, Ribeirão Preto, v. 3, n. 2, p.19-35, julho 1995. 